\title{
INBREEDING IN THE GREAT TIT
}

\author{
M. G. BULMER \\ Department of Biomathematics, University of Oxford
}

Received 1.vi.72

\begin{abstract}
SUMMARY
Data are presented on the frequency of close inbreeding and on inbreeding depression in a Great Tit population in Wytham Wood near Oxford. A theoretical distribution is fitted to data on the dispersal of young birds, and a model is constructed to predict the amount of inbreeding expected in a large, uniform habitat in terms of the dispersal distribution and of the breeding structure of the population.
\end{abstract}

\section{InTRODUCTION}

For the past 25 years the Edward Grey Institute of Field Ornithology has pursued a population study of the Great Tit (Parus major) in Wytham Wood near Oxford. Many nest-boxes have been put up, each of which is regularly visited in the breeding season. The clutch size and the number of young fledged are thus known for each breeding pair. The mother is also caught and ringed when she is sitting on the eggs, and the young are ringed about a fortnight after hatching. Since 1964 the more difficult task of catching and ringing the father, who does not sit on the eggs, has been accomplished in many cases. For further information on this study the reader is referred to Perrins (1965) and Lack (1966). A comparable Dutch study is described by Kluijver (1951). The purpose of this paper is to use the genealogical information available from 1964 onwards to estimate the amount of close inbreeding in this population, and then to construct a theoretical model which will predict the amount of inbreeding in a large, uniform habitat in terms of the dispersal of young birds from their birthplaces and of the age structure of the breeding population. Some limited data on inbreeding depression will also be presented.

\section{ThE FREQUENCY OF INBREEDING}

There were 397 matings between 1964 and 1970 for which both parents were caught. (Pairs breeding together in two or more years were counted only once.) A pedigree was constructed for each of these matings and was traced back as far as it could be taken. As a result, 7 consanguineous matings were discovered, composed as follows:

3 brother-sister matings, the sibs belonging to the same brood in each case,

2 mother-son matings,

1 aunt-nephew mating, a female being mated to the son of her sister from the same brood as herself,

1 greataunt-grandnephew mating, a female being mated to the grandson of her full brother born the year before her. 
The coefficient of inbreeding in the population calculated from the above figures is

$$
F=\left(3 \times \frac{1}{1}+2 \times \frac{1}{4}+1 \times \frac{1}{x}+1 \times \frac{1}{16}\right) 397=0.0036 .
$$

This can be regarded only as a lower limit to the truc amount of close inbreeding since many of the pedigrecs are very incomplete. There are two reasons for the incompleteness of the pedigrces. Firstly, many birds had not been ringed as nestlings but were first ringed either as brecding birds or through being trapped in the winter, so that their ancestry is unknown. It seems likely that nearly all of these birds, which will be called immigrants as opposed to residents, were born outside the study area, though not necessarily far outside. Of the 397 matings analysed, 101 were between two resident birds, 113 between a resident malc and an immigrant female, 64 between an immigrant malc and a resident female, and 119 between two immigrant birds. Thus the frequency of immigrant birds is 46 per cent. in males and 58 per cent. in females; the higher incidence in females is accounted for by their greater tendency to disperse, as shown in Section 4. The second reason for the incompleteness of the pedigrees is that the male parent may not have been caught; the male is almost never known for matings before 1964 and in only about two-thirds of the matings after 1964.

We rnust now consider the probable effect of the incompleteness of the pedigrees on the ascertainment of consanguineous matings. It scems likcly that most if not all of the brother-sister matings have been found. In all the matings between two resident birds it is known for certain whether or not they are sibs. Since Great Tits usually breed either in the same place or very near in successive years, it is very unlikely that a mating between a resident and an immigrant bird is a brother-sister mating. It is also rather unlikely that a mating between two immigrant birds should be a brothersister mating, since such matings are usually between birds that have moved only a short distance from their birthplace. For similar rcasons it is likcly that all the mother-son matings have been found. For if a mother mated with her son in the study arca, then she must almost certainly have raised that son in the study area, so that he is a native bird. In all matings of a native male with any type of female it is known for certain whether or not that female is his mother By the same argument father-daughter matings will almost ccrtainly occur among the matings with a native female, but they will only be ascertained if that female's father has been caught; there might therefore be one or two undetected father-daughter matings, but on the other liand one would expect fewer father-daughter than mother-son matings since young females disperse further than young males. If we combine together the closest relatives (brother-sister and parent-child) it can be concluded that the true frequency of this type of matirg does not greatly excecd the obscrved frequency of five pairs, which gives an incidence of $1 \frac{1}{4}$ per cent. Ascertainment in the case of less close relatives is likely to be very incomplete, and no reliable conclusions can be drawn about them.

Kluijver (1951) found two cases of brother-sister mating in his study of the Great Tit in Holland; the total number of matings examined is not clear, but his study was of about the same size as the present one. The most detailed investigation of inbreeding in other birds is that of Richdale (1957) or the yellow-eyed Penguin (Megadyptes antipodes); out of a total of 
244 matings he found 3 brother-sister, 1 halflorothcr-halfsister, and 3 secondcousin matings. In the Song-Sparrow (Melospiza melodia) Nice (1937) found I brother-sister mating, whereas Kendoigh (1941) found no cascs of inlorceding in his study of the. Housc Wren (Troglodytes aëdon). The total number of matings examined is not statcd exactly in either casc, but is probably smaller than in the present study.

In mammals, a considerably higher amount of inbrecding has bcen discovered by Howard (1949) in the Prairie Deermouse. (Peromyscus maniculatus bairdii). Howard found 10 instances of prcsumed closc inbrceding ( 8 fathcr-daughter matings and 2 between sibs) and 7 additional instances where closc inbreeding possibly occurred ( 2 betwecn father and daughter, 2 bctwcen mother and son, and 3 betwecn brother and sister). He concludes that " at least 4 to 10 per ccnt. of the littcrs observed were produced by parent-offspring matings or matings between sibs"'. The reason for this high amount of inbreeding is probabiy the low degrce of dispersal of young animals; only 31 per cent. of the malcs and 15 pcr cent. of the females moved inore than 500 feet (150 metres) from thcir birthplaccs to breed. The excess of father-daughter over mother-son matings can be explained by the higher degree of dispersal in the young males than in the young females of this spccics.

\section{INBREFDING DEPRESSION}

The five pairs with a coefficient of consanguity of 1 ( 3 brother-sister and 2 mother-son pairs) laid eight clutches with a total of 68 eggs, of which 42 hatched and then fledged successfully. The fledging success in these pairs is thus 62 per cent. and the fledging mortality 38 per cent. (This mortality includes both failure of the egg to hatch and nestling mortality.) One of these clutches, however, with seven eggs of which only one hatched and dicd bcfore fedging, had been attacked by a Great Spotted Wondpecker (Dendrocopos major) boring a hole through the nestbox at about the time when the eggs were due to hatch. Although none of the eggs or young was taken, it is possible that the failure of the eggs to hatch was due to disturb-. ance of the mother. If this clutch is excluded, the flcdging mortality bccomes 31 per cent. The fledging mortality in the whole population in the pcriod 1964-70, including as bcforc both failure to hatch and nestling mortality but excluding predated and second or rclaid clutchcs, was 17.5 per cent.

Although the mortality in inbred birds is bascd on a very small number of obscrvations, the above figurcs arc suggestive of an increase in the mortality due to inbrceding. If wc take these figures at thcir facc value, and assume that $-\ln S=A+B F$, where $S$ is the probability of survival among birds with inbreeding coefficient $F$ (Morton, (Crow and Muller, 1956), the cocfficients $A$ and $B$ can be estimatcd as $A=0.19$ and $B=1 \cdot 16$ (including the woodpcckered clutch) or 0.72 (excluding the woodpcckercd clutch). Since $B$ provides a lower cstimate of the number of lethal equivalents per gamcte, it can be concluded that there arc about 2 lethal cquivalents per zygote, that is to say per bird. This estimate is in good agrcement with estimatcs of the rffect of inbrceding on mortality in Drosiphila (Dobzhansky, 1970) and in man (Cavalli-Sforza and Bodmcr, 1970). In the Japanese Quail (Coturnix coturnix jafonica) Sittmann, Abplanalp and Frascr (1966) 
have obtained an estimate of 3.4 lethal equivalents per bird, based on hatchability and mortality in the first five weeks of life, which corresponds approximately with fledging mortality considered here.

We turn now to the effect of inbreeding on survival after fledging and on subsequent fertility. Of the 42 inbred birds which fledged successfully, none was recorded as breeding birds in subsequent years. In the general population, on the other hand, over the period $1964-70,7 \cdot 8$ per cent. of the fledglings were subsequently recorded as breeding birds, so that the expected number of recoveries from 42 fledglings is 3.3 . If we assume that the actual number of recoveries follows a Poisson distribution, then the probability that no birds will be recovered is $e^{-3 \cdot 3}=0 \cdot 037$. There is thus a significant deficiency in the number of breeding recoveries from the inbred birds, although the numbers involved are clearly too small to allow an estimate of the size of the deficiency. The deficiency may be due either to increased mortality after fledging or to decreased fertility in the inbred birds. Sittmann et al. (1966) found a marked reduction in fertility among inbred Japanese Quail. The same phenomenon is well-known in Drosophila (Dobzhansky, 1970).

\section{Dispersal of young birdS}

The most important factor determining the amount of inbreeding is the dispersal of young birds from their birthplaces to their first breeding-places; as already mentioned adult birds tend to stay in the same. breeding-place or very near from year to year as long as they live. The histograms of these dispersal distances for male and female birds are shown in figs. 1 and 2; the main deficiency of these data is that they do not include birds which have moved out of the study area, but this will not greatly affect the shape of the distribution near the origin which is of most importance in determining the amount of inbreeding.

Malécot (1967) has described a family of theoretical distributions, called $K$ distributions, which are very useful for fitting to dispersal data. A $K$ distribution with parameters $h$ and $b$ is defined by the density function

$$
f(r ; h, b)=\frac{h(h r)^{b} K_{b-1}(h r)}{2^{b-1} \Gamma(b)}, \quad r \geqq 0 ; h, b>0 .
$$

The cumulative probability function is

$$
F(r)=\int_{0}^{r} f(u) d u=1-\frac{(h r)^{b} K_{b}(h r)}{2^{b-1} \Gamma(b)} .
$$

In these formulae $r$ is the dispersal distance, $h$ is a scale parameter, $b$ is a parameter determining the shape of the distribution, and $K_{v}$ is the modified Bessel function of the second kind of order $\nu$. When $0<b<\frac{1}{2}$ the distribution is infinite at $r=0$, when $b=\frac{1}{2}$ it is an exponential distribution, and when $b>\frac{1}{2}$ it is an ordinary unimodal distribution. When $b$ becomes large and the scale parameter, $h$, is suitably adjusted, the distribution tends to the limiting form

$$
g(r)=\frac{r}{V} e^{-r^{2 / 2 V}},
$$

which is the distribution expected if the dispersal, when expressed in 


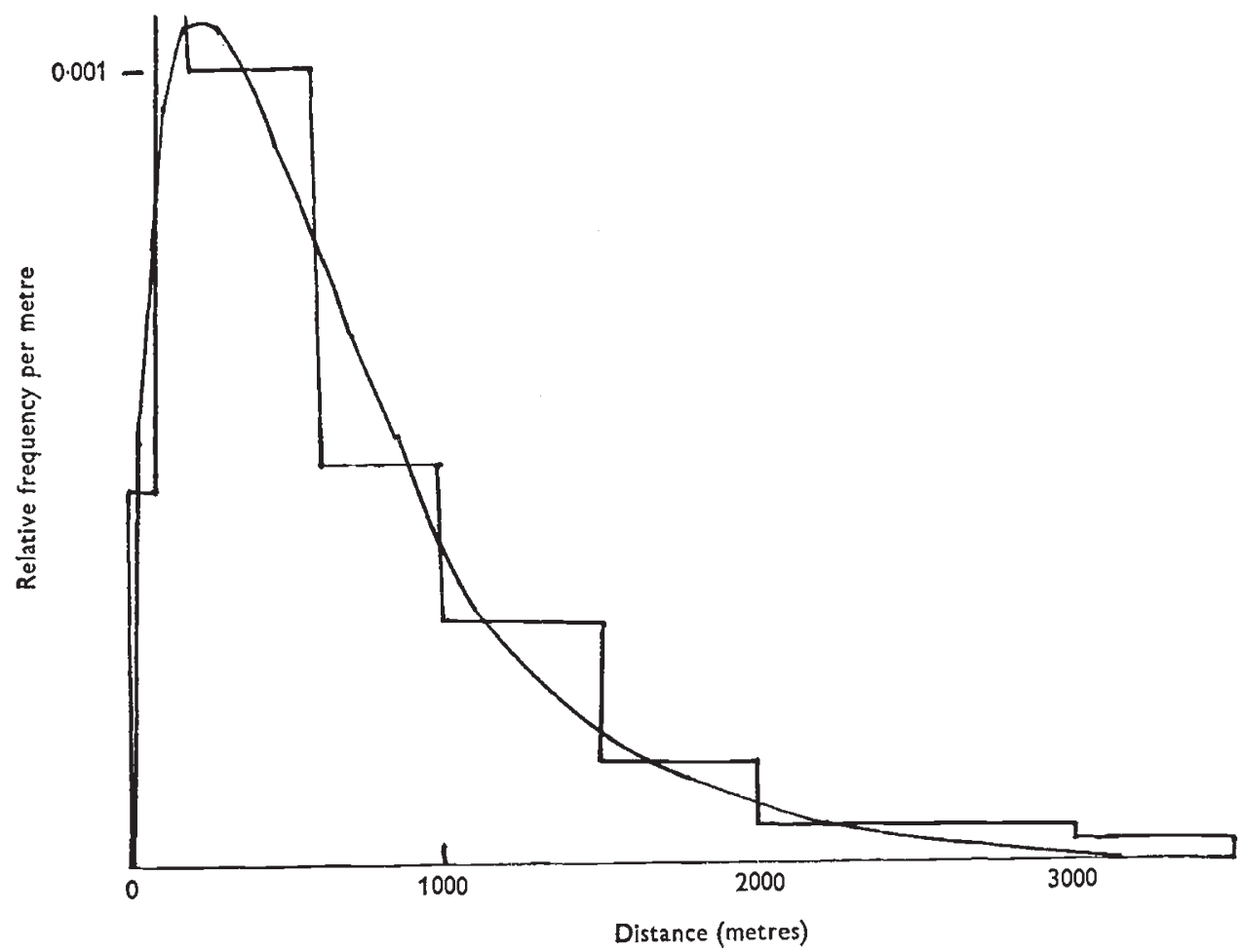

FIG. 1.-Dispersal from birthplace to first breeding-place in 240 male birds. Mean $=702$ metres, median $=475$ metres, variance $/$ mean $^{2}=0.78$. The superimposed curve is a $K$ distribution with $h=1 / 440, b=1$.

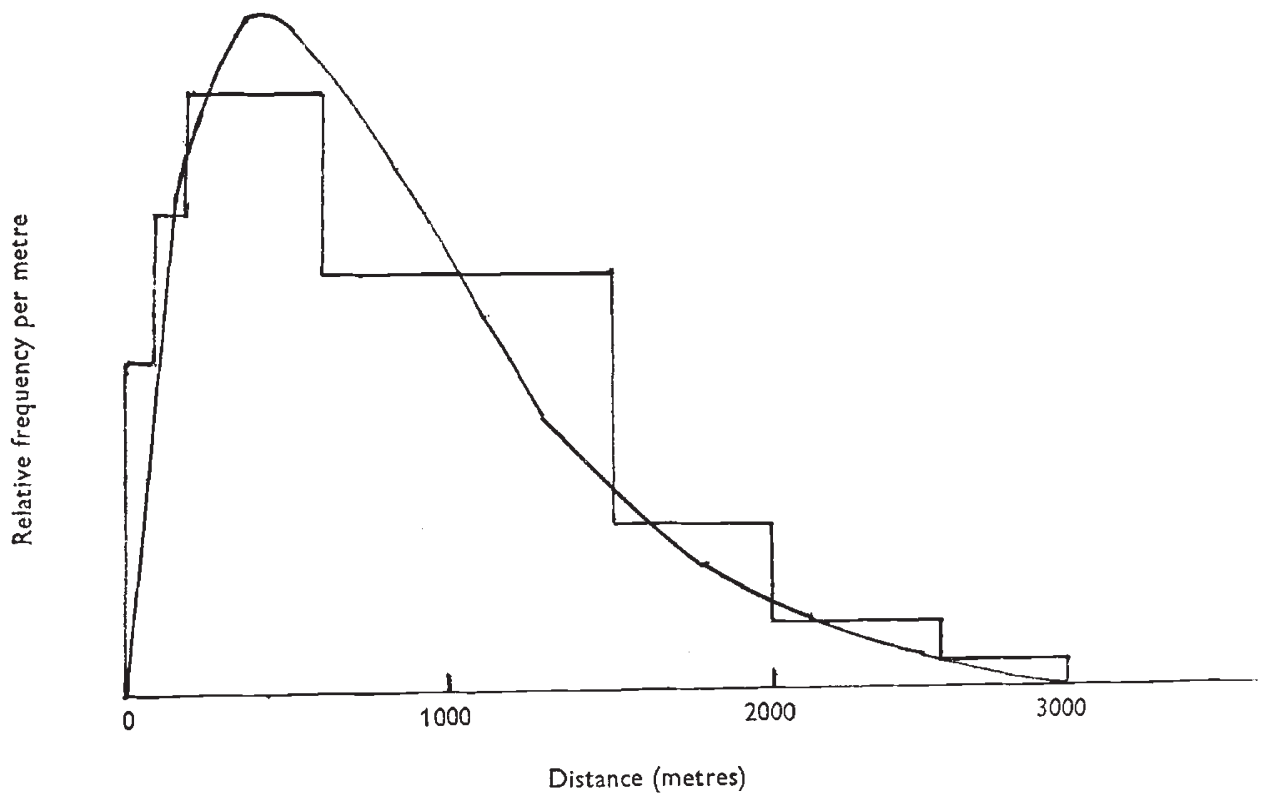

FIG. 2.-Dispersal from birthplace to first breeding-place in 171 female birds. Mean $=864$ metres, median $=775$ metres, variance $/$ mean $^{2}=0.49$. The superimposed curve is a $K$ distribution with $h=1 / 440, b=1 \frac{1}{2}$.

$30 / 3-X 2$ 
Cartesian coordinates, $x$ and $y$, follows a bivariate normal distribution with equal variances, $V$, for $x$ and $y$ and with no correlation between them.

The family of $K$ distributions is thus useful for fitting to dispersal data which are more skew than the moderately skew standard distribution given in equation 3 based on the assumption of an underlying bivariate normal distribution; such data are often found to be highly skew. A simple model giving rise to $K$ distributions is that dispersal is a two-dimensional diffusion process (random walk), but that the time during which dispersal occurs is also a random variable following a gamma distribution with parameter $b$ (or a $\chi^{2}$ distribution with $2 b$ degrees of freedom). The case when $b=1$, which corresponds to an exponential distribution for the dispersal time, has been considered by Broadbent and Kendall (1953) and by Pielou (1969). The first two moments about the origin of the $K$ distribution with parameters $h$ and $b$ are

$$
\begin{aligned}
E(r) & =2 \Gamma\left(b+\frac{1}{2}\right) \Gamma\left(1 \frac{1}{2}\right) / h \Gamma(b) \\
E\left(r^{2}\right) & =4 b / h^{2} .
\end{aligned}
$$

These formulae can be used to fit a $K$ distribution by the method of moments. The most valuable property of the $K$ distributions is that they can be convoluted in the following way. Suppose that movement occurs from $A$ to $B$ according to a $K$ distribution with parameters $h_{1}$ and $b_{1}$, and that a further movement occurs from $B$ to $C$ according to another, independent $K$ distribution with parameters $h_{2}$ and $b_{2}$; if the direction of movement is random in both cases, and if furthermore the scale parameters of the two distributions, $h_{1}$ and $h_{2}$, have the same value, $h$, then the distance between $A$ and $C$ will also follow a $K$ distribution with scale parameter $h$ and with $b=\left(b_{1}+b_{2}\right)$. This reproductive property allows us to follow the effect of dispersal over any number of generations.

In order to take advantage of this reproductive property it is desirable, if possible, to fit $K$ distributions with the same scale parameter to the data of figs. I and 2. It is also desirable that the parameter $b$ should be an integer or a half-integer since the Bessel functions are extensively tabulated in these cases; when $b$ is a half-integer the Bessel functions can also be expressed in terms of elementary functions. Values of the parameters which meet these requirements and which also predict the first two moments of the distributions fairly closely are $h=1 / 440$ for both distributions and $b=1$ for males and $1 \frac{1}{2}$ for females. It will be seen from figs. I and 2 that these $K$ distributions are in good agreement with the observed data. The female distribution, with $b=1 \frac{1}{2}$, is, apart from the scale factor, a $\chi^{2}$ distribution with 4 degrees of freedom.

The reproductive property of the $K$ distribution depends on the assumptions that dispersal occurs over a large uniform habitat. Neither of these assumptions is fulfilled in the present case since Wytham Wood is isolated from other woodland by urban and agricultural land, and since it is itself subdivided with a large park in the middle (see Perrins, 1965 for a map of the study area). It is therefore of interest to see whether the distributions of dispersal distances can be added together in the way described above. Table I shows the mean distance between $(a)$ the breeding-places of sisters born in the same year, $(b)$ the breeding-places of brother-sister pairs born in the same year, and $(c)$ the birthplaces of mates. If the distributions are additive, then the first distribution should be a $K$ distribution with $h=1 / 440$ 
and $b=3$, while the second and third distributions should both be $K$ distributions with $h=1 / 440$ and $b=2 \frac{1}{2}$. The mean distance is considerably smaller than its predicted value in all three cases; this result can most plausibly be attributed to the limited size and broken nature of the habitat.

TABLE 1

Mean distances (in metres) between breeding-places of sibs and birthplaces of mates

\begin{tabular}{lccc}
\multicolumn{1}{c}{ Distance measured } & Mean distance & Predicted \\
Breeding-places of sisters & 110 & $968 \pm 66$ & mean \\
Breeding-places of brother-sister pairs & 88 & $875 \pm 59$ & 1296 \\
Brithplaces of mates & 98 & $935 \pm 80$ & 1173 \\
& &
\end{tabular}

\section{A MODEL OF INBREEDING IN A LARGE, UNIFORM HABITAT}

The purpose of this section is to construct a model to predict the amount of inbreeding expected in a large, uniform habitat. It will be assumed that the dispersal of young birds follows a $K$ distribution as shown in figs. 1 and 2, and that these distributions can be convoluted over several generations in the way described in the previous section. The results obtained will not be applicable to a semi-isolated, broken habitat such as Wytham Wood, but they should be valid in a large forest and may thus be representative of the conditions prevailing in primaeval woodland prior to disturbance by man.

In addition to the pattern of dispersal it is also necessary to specify the breeding structure of the population. Detailed information on this subject is being published elsewhere (Bulmer and Perrins, 1973), but the following simplified assumptions will be made here:

1. The annual adult mortality is 50 per cent. independent both of age and sex. (In fact, mortality is slightly higher in females than in males but this complication will be ignored.) The age distribution in the adult population is thus a geometric distribution, the probability of a bird of age $x$ being $\left(\frac{1}{2}\right)^{x}, x \geqslant 1$.

2. All adult birds breed. The pair-bond, once formed, is broken only by death. A bird which is unpaired at the beginning of the breeding season, either because it is a first-year bird or because its previous partner has died, pairs at random, as far as age is concerned, among unpaired birds of the opposite sex. If $\phi(x, v)$ denotes the conditional probability that a bird known to be of age $x$ is mated to a bird of age $v$, it follows from elementary probability considerations that

$$
\begin{aligned}
& \phi(1,1)=\frac{2}{3} \\
& \phi(1, v)=\frac{2}{3} \times\left(\frac{1}{2}\right)^{v}, v \geqslant 2
\end{aligned}
$$

since all the first-year birds but only half of the older birds are unpaired at the beginning of the breeding season, and that, for $x \geqslant 2$,

$$
\begin{gathered}
\phi(x, 1)=\frac{1}{2} \phi(1,1)=\frac{1}{3} \\
\phi(x, v)=\frac{1}{2} \phi(x-1, v-1)+\frac{1}{2} \phi(1, v)=\frac{1}{2} \phi(x-1, v-1)+\frac{1}{3} \times\left(\frac{1}{2}\right)^{v}, v \geqslant 2
\end{gathered}
$$

since there is a probability of one-half that the pair-bond will have been broken by the death of the other partner. The unconditional probability that a mating will be between a bird of age $x$ and a bird of age $v$ is

$$
\psi(x, v)=\left(\frac{1}{2}\right)^{x} \phi(x, v) .
$$


3. Each breeding pair has one clutch each year, but about one-third of these clutches is lost by predation. (This was the average predation rate in Wytham Wood, but it is perhaps rather higher than is typical in holenesting species; see, for example, Lack (1954). Predated clutches may be relaid, but it seems reasonable to ignore these relaid clutches in view of their high mortality.) To maintain a stable population size each pair must raise on average one offspring which survives to reproduce in the following year, so that there must be on average 1.5 surviving young from each nonpredated clutch. It will be assumed that the number of surviving young from non-predated clutches follows a Poisson distribution with mean 1.5. It follows that an individual will have on average 1.5 sibs of the same age and $0 \cdot 25^{|z|}$ full sibs who differ in age by $z$ years $(z \neq 0)$, since the probability that both parents are alive $z$ years later (or by symmetry $z$ years previously) is $0 \cdot 25^{z}$. By a similar argument the average number of half-sibs who differ

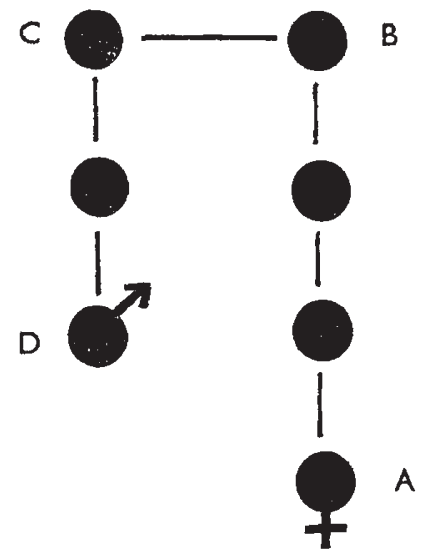

Fic. 3.-Pedigree of second cousins once removed.

in age by $z$ years is $2\left(0 \cdot 5^{|z|}-0 \cdot 25^{|z|}\right)$. The average number of full and halfsibs who differ in age by $z$ years will be denoted by $S_{F}(z)$ and $S_{H}(z)$ respectively. These averages include all sibs who survived to breed, regardless of whether they are at any particular time alive or dead.

Consider now the pedigree shown in fig. 3 in which $B$ and $C$ are full sibs so that $A$ and $D$ are second cousins once removed. The sexes of $A$ and $D$, but not of the other individuals, are specified. There are three links between $A$ and $B$, and two links between $C$ and $D$; in a general pedigree these numbers will be denoted by $i$ and $j$. If the female $A$ is now of age $x$, the probability that $B$ was of age $y$ when $A$ was born, and is therefore now of age $x+y$, is given by the convolution of $i$ geometric distributions, and is thus

$$
P_{i}(y)=\left(\begin{array}{l}
y-1 \\
y-i
\end{array}\right)\left(\frac{1}{2}\right) y, \quad y \geqslant i .
$$

This probability must be multiplied by $2^{i}$, since there are $2^{i}$ individuals like $B$. The average number of full sibs of $B$ who are now of age $x+y+z$ is $S_{F}(z)$. Finally, for each sib the average number of living direct descendants like $D$, who are of age $x+y+z-u=v$, is $2^{j-1} P_{j}(u)\left(\frac{1}{2}\right)^{v-1}$. Hence the average number of living relatives of type $D$ of age $v$ given that $A$ is of age $x$ is

$$
R(x, v)=2^{n-1}\left(\frac{1}{2}\right)^{v-1} \sum P_{i}(y) S_{F}(z) P_{j}(u),
$$


where $n=i+j$ and where the summation is to be taken over $y \geqslant i, u \geqslant j$, and with $z$ such that $x+y+z-u=v$. For half-sibs $S_{F}(z)$ must of course be replaced by $S_{H}(z)$. This expression must be doubled when $i \neq j$ if we do not wish to distinguish whether the female occurs in the long or the short chain of the pedigree.

Let us now suppose for the moment that there are $\mathcal{N}$ breeding pairs in the population and that mating is panmictic. Since there are $\mathcal{N} / 2^{v}$ males of age $v$ in the population, the conditional probability that a mating between a female of age $x$ and a male of age $v$ will be a consanguineous mating of the type being considered is $2^{v} R(x, v) / \mathcal{N}$. The probability of a mating between birds of these ages is given by $\psi(x, v)$ defined in equation 7 . Hence the overall frequency of this type of mating is given by $\alpha / \mathcal{N}$, where

$$
\alpha=2^{n} \sum P_{i}(y) S_{F}(z) P_{j}(u) \psi(x, v),
$$

the summation being taken over $x \geqslant 1, y \geqslant i, u \geqslant j$, and over all $z$ such that

TABLE 2

Predicted frequency of consanguineous matings related through full or half-sibs

\begin{tabular}{|c|c|c|c|c|c|}
\hline \multirow[b]{2}{*}{ Relationship } & & & \\
\hline & Full & Half & Full & Half & $N$ \\
\hline Sibs & $0 \cdot 80$ & 0.20 & 0.0028 & 0.0007 & 288 \\
\hline Uncle-niece or aunt-nephew & 0.91 & $1 \cdot 18$ & 0.0017 & $0 \cdot 0023$ & 524 \\
\hline First cousins & $1 \cdot 67$ & 1.05 & 0.0022 & $0 \cdot 0014$ & 762 \\
\hline $\begin{array}{l}\text { Greatuncle-grandniece or greataunt- } \\
\text { grandnephew }\end{array}$ & $0 \cdot 61$ & 1.41 & 0.0008 & 0.0018 & 762 \\
\hline First cousins once removed & 3.85 & 3.92 & 0.0039 & 0.0039 & 1000 \\
\hline Second cousins & $4 \cdot 80$ & $4 \cdot 02$ & 0.0039 & 0.0032 & 1241 \\
\hline $\begin{array}{l}\text { Greatgreatuncle-greatgrandniece or } \\
\text { greatgreataunt-greatgrandnephew }\end{array}$ & $0 \cdot 40$ & 1.34 & 0.0004 & 0.0013 & 1000 \\
\hline First cousins twice removed & 3.65 & $5 \cdot 38$ & 0.0029 & 0.0043 & 1241 \\
\hline Second cousins once removed & 13.96 & $14 \cdot 18$ & 0.0094 & $0 \cdot 0096$ & 1480 \\
\hline Third cousins & $15 \cdot 70$ & $14 \cdot 81$ & 0.0091 & 0.0086 & 1720 \\
\hline
\end{tabular}

$x+y+z-u \equiv v \geqslant 1$. (The provisos contained in the last two sentences of the preceeding paragraph also apply.) $\alpha$ may be interpreted as the average number of marriageable relatives of a given type, and is tabulated in table 2.

To incorporate the effect of dispersal into the model let us suppose that there are $m$ males and $n-m$ females among the intermediate birds linking $A$ and $D$; the probability of this is $\left(\begin{array}{l}n \\ m\end{array}\right) 2^{-n}$. The probability distribution, $M(r)$, of the distance between the birthplaces of $A$ and $D$ will be a $K$ distribution with $h=1 / 440$ and $b=(3 n-m) / 2$. Hence the average number of living relatives like $D$ of age $v$ given that $A$ is of age $x$ (the number of intermediate males being specified) whose birthplace is at a distance between $r$ and $r+d r$ from the birthplace of $A$ is

$$
\left(\begin{array}{l}
n \\
m
\end{array}\right) 2^{-n} R(x, v) M(r) d r,
$$

while the number of males of age $v$ whose birthplace is at a distance between $r$ and $r+d r$ from the birthplace of $A$ is $\left(\frac{1}{2}\right)^{2} 2 \pi r \delta d r$, where $\delta$ is the density of breeding pairs per square metre. Given that a mating has occurred between 
individuals whose birthplaces lie at a distance within this interval, and that the ages of the birds are $x$ and $v$ respectively, the probability that the birds are related in the way specified (the number of intermediate males also being specified) is

$$
\left(\begin{array}{l}
n \\
m
\end{array}\right) 2^{-n} R(x, v) M(r) 2^{v} / 2 \pi r \delta
$$

Averaging over $x$ and $v$ with probability $\psi(x, v)$ the probability becomes

$$
\alpha\left(\begin{array}{l}
n \\
m
\end{array}\right) 2^{-n} M(r) / 2 \pi r \delta .
$$

The probability that the distance between the birthplace of mates lies between $r$ and $r+d r$ is $f(r) d r$, where $f(r)$ is the density function of a $K$ distribution with $h=1 / 440$ and $b=2 \frac{1}{2}$. Hence the total probability of a consanguineous mating of this type (the number of intermediate males still being fixed) is

$$
\frac{\alpha}{2 \pi \delta}\left(\begin{array}{l}
n \\
m
\end{array}\right) 2^{-n} \int_{0}^{\infty} \frac{M(r) f(r)}{r} d r .
$$

The integral in the above expression is a special case of a standard integral quoted in Erdélyi (1954, Vol. 2, p. 334, equation 48) and takes the simple form

$$
\int_{0}^{\infty} \frac{M(r) f(r)}{r} d r=h^{2} /(3 n+3-m) .
$$

Summing over $m$, the predicted frequency of this type of consanguineous mating is therefore

$$
\frac{\alpha h^{2} 2^{-n}}{2 \pi \delta} \sum_{m=0}^{n} \frac{\left(\begin{array}{l}
n \\
m
\end{array}\right)}{(3 n+3-m)} .
$$

When $i \neq j$ this expression must as before be doubled if we do not wish to distinguish between a female on the short or long arm of the chain. The constant $h^{2}$ is equal to $1 / 440^{2}$, while $\delta$, the density of breeding pairs, was $0.79 /$ hectare or $0.79 \times 10^{-4} /$ square metre in Wytham Wood, so that $h^{2} / 2 \pi \delta=1 / 96$.

The above argument breaks down in the case of a brother-sister mating, but the result remains valid. This can be shown by writing $M(r)$ for the dispersal distribution of a male from birthplace to breeding-place, and $f(r)$ for the corresponding dispersal distribution of his sister; the argument of the preceding two paragraphs now remains valid with appropriate change of terminology, so that the predicted frequency of brother-sister matings is $\alpha / 96 \times 3$.

The predicted frequencies calculated from equation 16 are shown in table 2. The effect of dispersal can be seen from the effective number of breeding pairs, $\mathcal{N}$, shown in the last column, which has been calculated by equating $\alpha / \mathcal{N}$, the frequency expected in a panmictic population with $\mathcal{N}$ breeding pairs, to the predicted frequency. It must be stressed that these predicted frequencies are only applicable in a large, uniform habitat, and that the frequencies in a broken, semi-isolated habitat like Wytham Wood 
may be considerably higher; thus the observed frequency of brother-sister matings in Wytham Wood was $3 / 397=0.008$ which is almost three times the predicted frequency. This is to be expected from the facts about the distribution of the distance between the breeding-places of brother-sister pairs discussed at the end of the previous section. In fact, the observed distance between the breeding-places of brothers and sisters is approximately a $K$ distribution with $h=1 / 440$ but with $b=1 \frac{1}{2}$ instead of $2 \frac{1}{2}$; the effect of this can be mimicked by supposing that dispersal distances in brothers and sisters can be convoluted but that the dispersal distribution has $b=\frac{1}{2}$ for males and $b=1$ for females. If we follow the argument of the preceding paragraph with these values, we find that the predicted frequency of brothersister matings is $\alpha / 96=0.0083$, which is in very good agreement with the observed frequency.

Consider now the pedigree shown in fig. 4 in which $A$ is the greatgranddaughter of $D$. The sexes of $A$ and $D$, but not of the other individuals

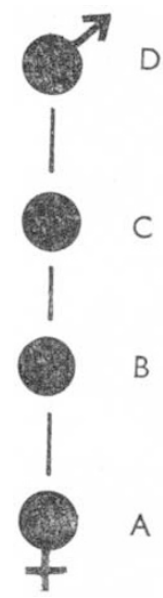

FIG. 4.-Pedigree of great-granddaughter and great-grandfather.

are specified. There are three links between $A$ and $D$; in a general pedigree of this kind it will be supposed that there are $n \operatorname{links,~so~that~} A$ has $2^{n-1}$ ancestors like $D$ of specified sex. In a general pedigree it will also be supposed that $B$ is the parent of $A$, and that $C$ is the child of $D$. If the female $A$ is now of age $x$, the probability that $C$ was of age $y$ when $A$ was born and hence is now of age $x+y$ is $P_{n-1}(y)$. The chance that $D$ was of age $z$ when $C$ was born and hence is now of age $x+y+z=v$ is $\left(\frac{1}{2}\right)^{z}$, and the chance that $D$ is still alive is $\left(\frac{1}{2}\right)^{x+y}$ since he was known to be alive when $C$ was born. Hence the average number of living ancestors like $D$ of age $v$ given that $A$ is of age $x$ is

$$
R(x, v)=2^{n-1}\left(\frac{1}{2}\right)^{v} \sum_{y \geqslant n-1} P_{n-1}(y) .
$$

By the same argument as before we find that

$$
\alpha=2^{n-1} \sum P_{n-1}(y) \psi(x, v),
$$

the summation being taken over $x \geqslant 1, y \geqslant n-1, v \geqslant x+y+1$. This expression must be doubled if we do not wish to distinguish between, for example, a 
grandfather-granddaughter and a grandmother-grandson mating. Values of $\alpha$, which have the same interpretation as before, are shown in table 3 .

TABLE 3

Predicted frequency of consanguineous matings related by direct descent

\begin{tabular}{|c|c|c|}
\hline Relationship & $\alpha$ & $\begin{array}{l}\text { Predicted } \\
\text { frequency }\end{array}$ \\
\hline Father-daughter & $0 \cdot 26$ & 0.0025 \\
\hline Mother-son & 0.26 & 0.0070 \\
\hline Grandparent-grandchild & 0.35 & 0.0013 \\
\hline Greatgrandparent-greatgrandchild & 0.23 & $0 \cdot 0004$ \\
\hline greatgreatgrandchild & $0 \cdot 15$ & 0.0002 \\
\hline
\end{tabular}

To incorporate the effect of disperasl, let us write $M(r)$ for the distribution of the distance between the breeding-places of $B$ and $D$, which is a $K$ distribution with $h=1 / 440$ and $b=[3(n-1)-m] / 2$, where $m$ is the number of males in the connecting chain, and $f(r)$ for the distribution of the dispersal distance of $A$ from birthplace to breeding-place, which is a $K$ distribution with $h=1 / 440$ and with $b=1$ if $A$ is male and $b=1 \frac{1}{2}$ if $A$ is female. Since $A$ can only be mated to $D$ if $A$ returns to the breeding place of $D$, it follows by the same argument as before that the chance that $A$ will be mated to $D$ is

$$
\frac{\alpha h^{2} 2^{1-n}}{2 \pi \delta} \sum_{m=0}^{n-1} \frac{\left(\begin{array}{c}
n-1 \\
m
\end{array}\right)}{3(n-1)+m+\epsilon},
$$

where $\epsilon=0$ or 1 according as $A$ is male or female.

This argument breaks down for a parent-child mating, but an approximate answer can be found by multiplying the probability that the parent is available for mating, which is equal to $\alpha$, by the probability that the child moves a distance less than $1 / \sqrt{\pi \delta}$, since each bird may be thought of as holding a circular territory with area $1 / \delta$. The latter probability may be found from equation 2 and is equal to 0.027 for males and 0.0095 for females. The predicted frequencies of father-daughter and mother-son matings are thus 0.0025 and 0.0070 respectively; in 397 matings one would expect 1 father-daughter and 3 mother-son matings, which are in reasonable agreement with the observed figures ( 0 and 2 respectively). Predicted frequencies for other matings calculated from equation 19 are given in table 3 , although one would not expect them to be applicable to Wytham Wood since, apart from the parent-child matings just considered, they assume that $K$ distributions can be convoluted over two or more generations.

Acknowledgment.- I am grateful to the late Dr D. Lack and to Dr C. M. Perrins for allowing me free access to the data at the Edward Grey Institute, and for help and encouragement with this study.

\section{REFERENCES}

BROADBENT, S. R., AND KENDALL, D. G. 1953. The random walk of Trichostrongylus retortaeformis. Biometrics, 9, 460-466.

BUlmer, M. G., AND PERrins, c. M. 1973. Mortality in the Great Tit Parus major. Ibis, 115, $277-281$. 
CAvalli-sforza, L. L., AND bodmer, w. F. 1970. The Genetics of Human Populations. W. H. Freeman \& Co., San Francisco.

dobzhansky, т. 1970. Genetics of the Evolutionary Process. Columbia University Press, New York.

ERDÉLYI, A. 1954. Tables of Integral Transforms, 2 vols. McGraw-Hill, New York.

HOWARD, w. E. 1949. Dispersal, amount of inbreeding, and longevity in a local population of Prairie Deermice on the George Reserve, Southern Michigan. Contr. Lab. Vert. Biol. Univ. Mich., 43, 1-50.

KENDEIGH, s. c. 1941. Territorial and mating behaviour of the House Wren. Ill. Biol. Monog., $18,1-120$.

KLuijver, H. N. 1951. The population ecology of the Great Tit, Parus m. major L. Ardea, 39, 1-135.

LAGK, D. 1954. The Natural Regulation of Animal Numbers. Clarendon Press, Oxford.

LACK, D. 1966. Population Studies of Birds. Clarendon Press, Oxford.

MALÉCOT, G. 1967. Identical loci and relationship. Proc. Fifth Berkeley Symp. Math. Stat. Prab., 4, 317-332.

MORTON, N. E., CROW, J. F., AND MULLER, H. J. 1956. An estimate of the mutational damage in man from data on consanguineous marriages. Proc. Nat. Acad. Sci., U.S.A., 42, 855-863. NIGE, M. M. 1937. Studies in the life history of the Song Sparrow. Trans. Linn. Soc. New rork, 4, 1-247.

PERrins, C. M. 1965. Population fluctuations and clutch-size in the Great Tit, Parus major L. 7. Anim. Ecol., 34, 601-647.

Pielou, E. C. 1969. An Introduction to Mathematical Ecology. Wiley, New York. RICHDAle, L. E. 1957. A Population Study of Penguins. Clarendon Press, Oxford.

SITTMANN, K., ABPLANALP, B., AND FRASER, R. A. 1966. Inbreeding depression in Japanese Quail. Genetics, 54, 371-379. 